\title{
HUBUNGAN DUKUNGAN SUAMI DENGAN LAMA KALA 1 FASE AKTIF PERSALINAN PADA IBU BERSALIN DI KLINIK NAMIRA KOTA SEMARANG
}

\author{
Titik Kurniawati $^{1)}$, Widyah Setiyowati' ${ }^{2}$, Amaliyatul Fitriyah ${ }^{3)}$ \\ ${ }^{1,2,3}$ Prodi DIII Kebidanan, Universitas STEKOM Semarang \\ Email: kurniawati2233@yahoo.co.id
}

\begin{abstract}
ABSTRAK
Pendahuluan: Persalinan dan kelahiran merupakan kejadian fisiologi yang normal dalam kehidupan. Peranan ibu adalah melahirkan bayinya, sedangkan peran keluarga adalah memberikan bantuan dan dukungan pada ibu ketika terjadi proses persalinan. Tujuan dari penelitian ini adalah untuk mengetahui hubungan antara dukungan suami terhadap ibu bersalin dengan lamanya kala 1 fae aktif pada persalinan. Metode: Penelitian menggunakan rancangan Retrospektif yaitu penelitian berusaha melihat kebelakang (backword looking). Jenis penelitian korelasi yaitu meneliti atau menelaah hubungan antara dua variable pada suatu situasi atau sekelompok subjek. Jumlah subjek dalam penelitian ini sebanyak 15 responden ibu bersalin. Hasil: Terdapat 2 responden dengan umur di bawah 20 tahun, terdapat 12 responden ibu bersalin dengan pekerjaan sebagai ibu rumah tangga dan terdapat 10 responden dengan tingkat pendidikan yaitu SMA. Dan ibu bersalin yang mendapatkan dukungan suami yaitu sebanyak 14 $(93,3 \%)$ dan yang tidak mendapat dukungan suami yang hanya besar $1(6,66 \%)$. Kesimpulan: Terdapat hasil nilai $\mathrm{p}$ value lebih kecil dari $0,005(0,002<0,005)$ maka $\mathrm{H}_{\mathrm{o}}$ ditolak dan $\mathrm{H}_{\mathrm{a}}$ diterima berarti ada hubungan antara dukungan suami dengan lama kala I fase aktif pada ibu bersalin di Klinik Namira Kota Semarang.
\end{abstract}

Kata Kunci: Dukungan suami, lama kala 1 fase aktif

\begin{abstract}
Introduction: Labor and delivery are normal physiological events in life. The mother's role is to give birth to her baby, while the role of the family is to provide assistance and support to the mother when the labor occurs. The purpose of this study was to determine the relationship between husband's support for maternal and childbirth with the length of 1 period of active pregnancy during labor. Methods: The study used a retrospective design, namely research trying to look back (backword looking). This type of correlation research is examining or examining the relationship between two variables in a situation or group of subjects. The number of subjects in this study were 15 respondents who gave birth. Results: There were 2 respondents under 20 years of age, there were 12 respondents who gave birth as housewives and there were 10 respondents with education level, namely SMA. And mothers who gave birth who received support from their husbands were $14(93.3 \%)$ and only 1 (6.66\%) did not receive support from their husbands. Conclusion: There is a result that the $p$ value is smaller than 0.005 (0.002 <0.005), so Ho is rejected and Ha is accepted, it means that there is a relationship between husband's support and the duration of the active phase of the mother giving birth at NAMIRA clinic Semarang City.
\end{abstract}

Keywords: Husband's support, long period of 1 active phase

\section{PENDAHULUAN}

Setiap orang tua pasti mendambakan kehadiran buah hatinya, begitu pula dengan para ibu hamil yang mengalami perubahanperubahan fisik dari kehamilannya, pemahanman untuk mengurangi kecemasan ibu dalam proses persalinan. Wanita yang hamil 9 bulan siap untuk melahirkan dan agar berpartisipasi penuh dalam persalinan dan semestinya dia tahu akan semua kemungkinan yang bisa terjadi pada saat persalinan. Tetapi setiap pengalaman wanita secara hakiki bersikap pribadi dan individual, apakah dia melahirkan di rumah sakit, di bidan atau di klinik dan dengan atau tanpa obat-obatan, dengan atau tanpa kehadiran suami / pasangannya atau pada akhirnya dia sendiri harus memutuskan (Hardjana, A, M, 2000: 326). Persalinan dan kelahiran merupakan kejadian yang fisiologi yang normal dalam kehidupan. Kelahiran seorang bayi juga merupakan peristiwa sosial bagi ibu dan keluarga. Peranan ibu adalah melahirkan bayinya, sedangkan peran keluarga adalah memberikan bantuan dan dukungan pada ibu ketika terjadi proses persalinan. Dalam hal ini peranan petugas kesehatan tidak kalah penting dalam memberikan bantuan 
dan dukungan pada ibu agar seluruh proses persalinan berlangsung dengan aman baik bagi ibu dan bayi yang dilahirkan (Walyani, 2015). Persalinan adalah proses pengeluaran janin yang terjadi pada kehamilan cukup bulan (37-42 minggu), lahir spontan dengan presentasi belakang kepala yang berlangsung 18 jam-24 jam tanpa komplikasi baik pada ibu maupun pada janin. Pada setisp persalinan harus memperhatikan faktor-faktor yang mempengaruhinya. Tiga faktor yang menentukan prognosis persalinan adalah jalan lahir (passage), janin (passenger) dan kekuatan (power) dan ada dua faktor lain yang berpengaruh yaitu faktor posisi dan faktor psikologis (Prawiroharjo, 2005). Secara psikologis, istri membutuhkan pendampingan suami selama proses persalinan. Proses persalinan merupakan masa yang paling berat bagi ibu, dimana ibu membutuhkan dukungan dari berbagai pihak, terutama suami agar dapat menjalani proses persalinan sampai melahirkan dengan aman dan nyaman. Dukungan moral seorang suami pada istrinya adalah hal yang memang dibutuhkan. Sangat dianjurkan suami memberikan dukungan yang lebih besar kepada istrinya (Hardjana. A.M, 2000: 326). Seorang dukungan suami bisa mempengaruhi peristiwa persalinan itu sendiri dan perasaaan seorang ibu terhadap persalinannya. Kajian menunjukkan bahwa para ibu yang mendapatkan dukungan dari suami selama persalinan akan sedikit lebih memerlukan pereda nyeri, mengalami sedikit campur tangan medis, dan melahirkan bayi-bayi yang lebih kuat, setelah melahirkan juga dirinya akan merasa lebih baik dan tenang (Nolan 2003). Pada saat ini jumlah penduduk perempuan di Indonesia berjumlah sekitar 131,88 juta jiwa perempuan, untuk yang masuk dalam usia subur (15-45 tahun) 70. 250. 528. Dari jumlah penduduk perempuan terdapat 5.082.537 jiwa ibu bersalin dari jumlah penduduk perempuan di Indonesia (Sensus Penduduk 2017). Berdasarkan Profil Kesehatan Jawa Tengah tahun 2016, didapatkan bahwa Jawa Tengah terdiri dari 29 Kabupaten dan 6 Kota, yang tercakup dalam K-4 pada tahun 2016 sebanyak 93,26 $\%$ dan masih ada 5, $94 \%$ yang tidak mendapatkan pelayanan K-4 (Profil Kesehatan Jawa Tengah 2016). Menurut profil kesehatan kota semarang tahun 2016 didapatkan jumlah ibu bersalin ysng mendapatkan pertolongan kesehatan sebanyak 26.444 dari 26.444 persalinan (100\%). Angka ini sudah melampau target tahun 2016 (95\%). (Profil Kesehatan Kota Semarang). Berdasarkan hasil study pendahuluan yang dilakukan pada bulan Agustus dan 10 September 2019 di Klinik Namira didapatkan bahwa dari 15 proses persalinan, $6 \mathrm{ibu}$ bersalin primipara, $9 \mathrm{ibu}$ bersalin multipara dan 12 ibu bersalin didampingi oleh suami sedangkan 3 ibu bersalin tidak didampingi oleh suami (1 primipara dan 2 multipara). Terdapat beberapa faktor yang mempengaruhi kurangnya dukungan suami saat proses persalinan, salah satunya adalah kurangnya pengetahuan suami akan pentingnya pendampingan saat proses persalinan. Resiko dalam persalinan yang sering dijumpai yaitu perpanjang dari kelahiran bayi, partus lama, hal ini tidak terlepas dari faktor-faktor yang mempengaruhi persalinan yaitu: power, passage, passenger, psikis dan penolong. Faktor psikis dalam menghadapi persalinan merupakan faktor yang sangat mempengaruhi proses persalinan. Dukungan yang penuh dari anggota keluarga sangat penting bagi seorang Ibu bersalin terutama dukungan dari suami sehingga memberikan support moril terhadap Ibu (Walyani, 2015). Penelitian oleh Susanti (2017) diperoleh kategori dukungan suami sebagian besar tinggi, 21 orang $(84,0 \%)$. Pada tingkat kecemasan ibu menghadapi persalinan sebagian besar rendah, terdapat 16 orang $(64,0 \%)$. Dengan demikian ada kecenderungan bahwa ibu hamil menjelang persalinan dengan dukungan suami cederung tidak cemas, dengan nilai $\mathrm{p}=0,004$. Berdasarkan fenomena diatas penulis tertarik untuk meneliti "Hubungan Dukungan Suami Terhadap Lamanya Kala I pada Fase Aktif di Klinik Namira Gunungpati Semarang".

\section{METODE}

Penelitian ini menggunakan retrospeltif dengan menggunakan rancangan Retrospektif yaitu penelitian berusaha melihat kebelakang (backword looking). Jenis penelitian korelasi yaitu meneliti atau menelaah hubungan antara dua variable pada suatu situasi atau sekelompok subjek, penelitian ini termasuk penelitian survey, yaitu penelitian yang menggunakan sampel untuk mengambil kesimpulan pada populasi 
(Notoatmodjo, 2005). Populasi dalam penelitian ini adalah semua ibu bersalin baik primipara maupun multipara yang bersalin dari bulan September dan Oktober 2019 sejumlah 15 ibu. Jumlah sampel 15 ibu bersalin, dengan tehnik sampling yaitu sampel jenuh.

\section{HASIL}

\section{Gambaran Umum}

Terdapat 2 responden dengan umur dibawah 20 tahun, terdapat 12 responden ibu bersalin dengan pekerjaan sebagai ibu rumah tangga dan terdapat 10 responden dengan tingkat pendidikan yaitu SMA.

2. Analisis Univariat

a. Dukungan terhadap ibu bersalin

Tabel 1

Distribusi frekuensi dukungan suami terhadap ibu bersalin

\begin{tabular}{lcl}
\hline Dukungan Suami & Jumlah & $\%$ \\
\hline Mendapat & 14 & 93,3 \\
Tidak mendapat & 1 & 6,66 \\
\hline Total & 15 & yang tidak mendapat dukungan suami \\
\hline Bersadarkan tabel di atas diperoleh & yang hanya besar 1 (6,66\%) responden. \\
$\begin{array}{l}\text { informasi bahwa sebagian besar } \\
\text { responden mendapatkan dukungan }\end{array}$ & b. Lama kala I \\
suami yaitu sebanyak 14 (93,3\%) dan & &
\end{tabular}

Tabel 2

Distribusi Frekuensi Berdasarkan Lama kala I

\begin{tabular}{lcc}
\hline Lama Kala I Persalinan & Jumlah & $\%$ \\
\hline Normal & 15 & 100 \\
Tidak Normal & 0 & 0 \\
\hline Total & 15 & 100 \\
\hline
\end{tabular}

Berdasarkan tabel di atas diperoleh informasi bahwa sebagian besar responden dengan lama kala 1 persalinan normal sebanyak $15(100 \%)$ responden dan tidak normal $0(0 \%)$ responden.

\section{Analisis Bivariat}

Hubungan dukungan suami dengan lama kala I fase aktif persalinan pada ibu bersalin di Klinik Namira Gunungpati Semarang.
Berdasarkan responden yang mendapat dukungan suami, persalinan kala I cenderung cepat, sedangkan responden yang tidak mendapat dukungan suami cenderung lebih lambat, sehingga dikelompokkan menjadi persalinan dengan kala I sedang agar uji statistic Chi Square maupun Fisher's Exact bias digunakan, ini dapat dirangkum dalam tabel dibawah ini.

Tabel 3

Hubungan dukungan suami dengan lama kala I persalinan pada ibu bersalin di Klinik Namira Gunungpati.

\begin{tabular}{lcccccc}
\hline & \multicolumn{2}{c}{ Lama kala I persalinan } & \multicolumn{2}{c}{ Total } \\
\cline { 2 - 7 } Dukungan Suami & Normal & $\%$ & $\mathrm{~N}$ & $\%$ & $\mathrm{~N}$ & $\%$ \\
& $\mathrm{~N}$ & 93,3 & 0 & 0 & 14 & 93,3 \\
Mendapat dukungan & 14 & 0 & & 6,66 & 1 & 6,66 \\
Tidak mendapat & 1 & 93,3 & 0 & 6,66 & 15 & 100 \\
\hline Total & 15 & & & &
\end{tabular}

Berdasarkan tabel tersebut dapat disimpulkan bahwa terdapat 15 responden ibu bersalin, sebanyak $14 \quad(93,3 \%)$ responden mengalami kala I cepat karena mendapat dukungan dari suami dan 1 $(6,66 \%)$ responden mengalami kala I lama karena tidak mendapat dukungan dari suami.
Dalam penelitian ini menggunakan Uji Pearson Chi-Square menggunakan SPSS, digunakan dalam menganalisis hubungan dukungan suami dengan lamanya kala I fase aktif pada ibu bersalin di Klinik Namira Gunungpati, Semarang. Karena nilai $p$ value lebih kecil dari $0,005(0,002<$ 0,005) maka $\mathrm{H}_{\mathrm{o}}$ ditolak dan $\mathrm{H}_{\mathrm{a}}$ diterima 
berarti ada hubungan antara dukungan suami dengan lama kala I fase aktif pada ibu bersalin di Klinik Namira Gunungpati, Kota Semarang.

\section{PEMBAHASAN}

\section{Univariat}

a. Dukungan Suami

Berdasarkan hasil penelitian yang diperoleh informasi bahwa sebagian besar responden yang mendapat dukungan suami yaitu sebesar $14(93,3 \%)$, lebih besar dibandingkan yang tidak mendapat dukungan suami yang hanya sebesar $1(6,66 \%)$ responden.

Hal ini yang sesuai dengan pendapat Ratna (2010) bahwa dukungan suami yang mendampingi ibu selama proses persalinan sangat membantu mewujudkan persalinan yang lancar, dukungan yang dapat diberikan suami antara lain membantu ibu berganti posisi, mengajak ibu bercerita, melakukan rangsangan tekstil, memberikan makanan dan minuman, membantu ibu dalam mengatasi rasa nyeri dengan memijat bagian lumbal/pinggang belakang, dan memberikan kenyamanan, perhatian serta menenangkan hati ibu dalam menghadapi dan menjalani proses persalinan, sehingga dapat membantu memperlancar persalinan.

Dukungan emosional yang di berikan ibu bersalin dalam fase aktif yaitu:

1) Dorongan pasangan ibu yang melahirkan untuk mendukungnya (Suami)

2) Fasilitasi orang lain untuk ikut mendukung ibu bersalin bersama dengan keikut sertaan pasangannya.

3) Suami menguatkan dan menyakinkan ibu dalam proses persalinan.

b. Lama kala I fase aktif

Berdasarkan penelitian yang diperoleh bahwa dari 15 ibu bersalin didapatkan responden dengan lama kala I fase aktif normal sebanyak $14(93,3 \%)$ dan tidak normal sebanyak $1(6,66 \%)$ responden.
Pada fase ini frekuensi dan lama kontraksi uterus umumnya meningkat (Kontraksi dianggap adekuat atau memadai jika terjadi tiga kali atau lebih dalam waktu 10 menit dan berlangsung selama 40 detik atau lebih), serviks membuka dari $4 \mathrm{ke} 10 \mathrm{~cm}$ biasanya dengan kecepatan $1 \mathrm{~cm}$ atau lebih perjam hingga pembukaan lengkap (10 $\mathrm{cm}$ ), terjadi penurunan bagian terbawah janin. Gejala-gejala fase aktif adalah bertambahnya rasa tidak enak bersamaan dengan kontraksi, bertambahnya sakit punggung, rasa tidak nyaman pada kaki, keletihan, bertambahnya pengeluaran lendir dan darah, jika sebelumnya ketuban belum pecah, mungkin akan pecah saat ini, secara emosional Ibu gelisah, makin sulit tenang dan sulit santai, makin tegang tidak dapat berkonsentrasi, makin terpengaruh dengan kondisi yang sedang terjadi, rasa percaya diri mulai goyah, sepertinya persalinan tidak akan selesai, namun mungkin sebaliknya Ibu akan merasa bergembira dan semangat karena persalinan mulai terjadi (Manuaba, 2003).

\section{Bivariat}

Hubungan dukungan suami dengan lamanya kala I fase aktif persalinan pada ibu bersalin di Klinik Namira Gunungpati kota Semarang.

Hasil penelitian menunjukkan ada hubungan dukungan suami terhadap ibu bersalin pada kala I fase aktif di Klinik Namira Gunung pati Kota Semarang dengan nilai $p$ value lebih kecil dari 0,005 $(0,002$ $<0,005)$. Hal ini menunjukkan bahwa ibu bersalin yang mendapatkan dukungan suami saat persalinan mengalami lama kala I cepat dibanding yang tidak mendapat dukungan dari suami. Penelitian ini sejalan dengan penelitian Dina Fauti Pitarua (2010) yang menyatakan bahwa ada hubungan anatara dukungan suami terhadap ibu bersalin pada kala I fase aktif pada ibu bersalin dari peneliti bahwa dari 14 responden yang mendapatkan dukungan suami baik selama kala I 
persalinan sebanyak $12 \quad(85,7 \%)$ responden mengalami kala I yang cepat.

Dukungan suami selama persalinan merupakan dukungan fisik dan psikis yang diberikan suami pada ibu bersalin saat menghadapi persalinan. Persalinan adalah saat yang menegangkan dan dapat menggugah emosi ibu dan keluarga atau bahkan dapat menjadi saat yang menyakitkan dan menakutkan bagi ibu. Upaya untuk mengatasi gangguan emosional dan pengalaman yang menegangkan tersebut sebaiknya dilakukan melalui asuhan sayang ibu adalah dengan menganjurkan suami dan keluarga ibu untuk hadir dan memberikan dukungannya agar persalinan dapat berjalan dengan cepat dan lancar (JNPK-KR,2015).

Bagi ibu bersalin ketenangan merupakan hal yang penting dalam menghadapi persalinan. Suami dan keluarga medukung dan memotivasi istri untuk menjaga agar persalinan berada dalam kondisi sehat. Apabila ibu bersalin mengalami stress psikologi, maka janin dan ibu akan mengalami kondisi yang tidak baik. Stress psikologi yang dialami ibu dapat menyebabkan disekresinya epineprin yang menghambat aktifitas myometrial sehingga mengakibatkan tidak terkoordinasinya aktifitas uterus. Agar tidak terjadi kondisi tersebut support system dukungan keluarga orang yang terdekat atau suami sehingga dapat memainkan peranan terhadap wanita yang sedang melahirkan (Dinkes Kota Semarang, 2019).

\section{SIMPULAN DAN SARAN}

\section{Simpulan}

1. Ibu bersalin yang mendapatkan dukungan suami sebanyak 14 $(93,3 \%)$ responden

2. Lama kala I yang di alami responden normal yaitu sebanyak $15(100 \%)$ responden

3. Ada hubungan antara dukungan suami terhadap ibu bersalin dengan lamanya kala I fase aktif.
Dengan nilai $p$ value lebih kecil dari $0,005(0,002<0,005)$

\section{Saran}

Sebaiknya Dinas kesehatan membuat kebijakan dalam rangka peningkatan gerakan sayang ibu dengan program suami diperbolehkan mendampingi saat istri melahirkan di setiap tempat pelayanan kesehatan

\section{DAFTAR PUSTAKA}

Adi, R. 2004. Metodologi Penelitian Sosial dan Hukum. Granit. Jakarta.

Arikunto, S. 2002. Metodologi Penelitian Suatu Pendekatan Proposal. PT. Rineka Cipta. Jakarta.

Bruns, A. August. 2000. Pemberdayaan Wanita dalam Bidang Kesehatan. PT Yayasan Essentia Medica. Yogyakarta.

Chopra, D. 2006. Asuhan Kebidanan persalinan dan Kelahiran. ECG. Jakarta.

Dinas Kesehatan Kota Semarang. 2016. Profil Kesehatan Kota Semarang Tahun 2016. Dinkes. Semarang.

Dinas Kesehatan Provinsi Jateng. 2016. Profil Kesehatan Provinsi Jawa Tengah Tahun 2016. Dinas Kesehatan Provinsi Jateng. Jawa Tengah.

Dinas Kesehatan Kota Semarang. 2019. Buku Saku Kesehatan Kota Semarang Tahun 2019. Dinkes. Semarang.

Farrer, 2002. Perawatan Maternitas Edisi 2. EGC. Jakarta.

Friedman, 2003. Buku Ajar Keperawatan Keluarga. EGC. Jakarta.

Hidayat, Asri. 2010. Asuhan Kebidanan Persalinan. Nuha Medika. Yogyakarta.

Huliana, 2011. Panduan Menjalani Kehamilan Sehat. Puspa Swara. Jakarta

Indiarti M.T. 2008. Paduan Lengkap Kehamilan, Persalinan dan Perawatan Bayi. Diglossia Media. Yogyakarta.

Maulan. 2008. Promosi Kesehatan. EGC. Jakarta.

Nolan, Mary. 2003. Kehamilan dan 
Melahirkan. Arcan. Jakarta.

Notoatmodjo, S. 2005. Promosi

Kesehatan teori dan aplikasinya.

Rineka Cipta. Jakarta.

Prawirohardjo, Sarwono. 2005.

Asuhan Kebidanan Persalinan

Normal. Bina Pustaka. Jakarta.

Ratna, 2010. Metodologi Penelitian. Pustaka Pelajar. Yogyakarta.

Sumarah, 2008. Perawatan Ibu Bersalin. Asuhan Kebidanan Pada Ibu Bersalin. Fitramaya. Yogyakarta.

Suparni, dkk. 2016. Dukungan Suami pada Persalinan Preeklampsi Anik Wahidah Rahmah. Jurnal Ilmiah Kesehatan (JIK) Vol IX, No.2, September 2016

Susanti A. 2017. Hubungan Dukungan Suami Terhadap Tingkat Kecemasan Ibu Hamil Menjelang Persalinan di Ruang Persalinan Rumah Sakit Umum Daerah Karanganyar Tahun 2017.

file:///C:/Users/USER/Download s/JURNAL\%20APRIL\%20.pdf

Stoppard, M. 2008. Buku pintar kehamilan dan persalinan modern. Quills Book Publishers. Yogyakarta.

Sugiyono. 2007. Metodologi Peneliian Kuantitatif, Kualitatif, R\&D. Alfabeta Bandung.

Varney, Helen dkk. 2001. Buku Saku Bidan. EGC. Jakarta.

Varney H. 2007. Buku ajar ashuan kebidanan. EGC. Jakarta.

Walyani, Siwi. 2015. Asuhan Kebidanan Pada Kehamilan. Pustaka Baru Pres. Yogyakarta.

Yanti. 2010. Buku ajar kebidanan persalinan. Yogyakarta: Bina Pustaka 